\title{
Are Hedge Funds Uncorrelated With Financial Markets? An Empirical Assessment
}

Khaled Guesmi, IPAG Business School, France

Saoussen Jebri, EconomiX-University of Paris West la Défense, France

Abdelkarim Jabri, LERMA (ENCGO), Mohammed First University, Morocco

Frédéric Teulon, IPAG Business School, France

\begin{abstract}
In this paper, we examine the correlations between hedge fund strategy indices and asset classes. Based on the Dynamic Conditional Correlation (DCC) GARCH Model, we estimate the correlations between hedge fund, stock, and bond indices during bull and bear markets. The results reveal that there are significant correlations between hedge funds and the stock market, especially during the recent financial crisis that took place from 2007 to 2009.
\end{abstract}

Keywords: Hedge Funds; Stock Market; DCC-GARCH

\section{INTRODUCTION}

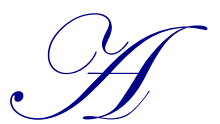

ccording to popular perception, hedge funds are investment vehicles whose main objectives are to deliver absolute returns to investors during both bull and bear markets resulting from their allegedly weak correlations with bond and stock markets. The benefit most often cited by portfolio managers is that hedge funds generate returns that are weakly correlated with the returns of mutual funds and standard asset classes. Having additional assets with weak or even negative correlations with markets allows for the diversification of risk in a mean-variance environment. This advantage explains the growing popularity of hedge funds among investors since the mid-1990s. However, during the recent financial crisis that took place from 2007 to 2009 , the bankruptcies of some hedge funds led the hedge fund industry to be severely criticized by regulators, investors, and the financial press expressing their concerns regarding this industry. These events naturally raise the question of whether hedge fund performance is really uncorrelated with markets. This is an important issue because investors need to know whether the claims of uncorrelated returns made by the hedge fund industry are actually "true" or merely a marketing gimmick.

Although numerous research papers have been written about the correlations between hedge funds and financial markets, their results vary widely. Some authors have found weak correlations, including Fung and Hsieh (1997) and Kat and Lu (2002). Fung and Hsieh (1997) showed that the weak correlation between the monthly returns of hedge funds and those of traditional asset classes are attributable to the nature of the trading strategies employed by hedge funds to achieve their goal of absolute performance.

Kat and $\mathrm{Lu}$ (2002) noted that hedge funds have a weak correlation with the S\&P 500 index and a near-zero correlation with the Salomon Brothers index. However, other studies have found strong correlations between hedge funds and standard assets (Mitchell and Pulvino, 2001; Brooks and Kat, 2002; Agarwal and Naik, 2004; Capocci et al., 2005; Boyson et al., 2010). Brooks and Kat (2002) showed that there are strong correlations between the majority of hedge fund and equity indices, particularly the Russell 2000. Agarwal and Naik (2004) also found strong correlations between merger arbitrage funds during bearish stock markets. This result is aligned with the findings of Mitchell and Pulvino (2001). Capocci et al. (2005) found a positive and significant correlation between hedge fund indices and equity market returns. Boyson et al. (2010) confirm these results, finding a strong correlation between 
the returns of hedge fund indices and the Russell 3000. This paper therefore aims to fill the gap in the existing empirical research regarding the claim that hedge funds generate uncorrelated returns.

Our analysis is based on the monthly returns of ten hedge fund strategy indices (emerging market, dedicated short bias, equity hedge strategy, equity market neutral, convertible arbitrage, event-driven, merger arbitrage, multi-strategy, and fund of funds). As main asset classes, the report uses global stocks, US stocks, European stocks, and US bonds. The performance of the asset classes is measured using the MSCI World Total Return Index (MSCI W), the S\&P 500 Total Return Index (SPX 500), the MSCI Europe Total Return Index (MSCI EUR), the JP Morgan Global Aggregate US Bond Total Return Index (JPMGG), and the JP Morgan Global Aggregate ex US Bond Total Return Index (JPMGGxUS).The sample period ranges from June 1997 to December 2011.

The remainder of the paper is organized as follows. Section 2 describes the data. Section 3 presents the empirical methodology. The results are reported and discussed in Section 4. Section 5 concludes.

\section{DATA DESCRIPTION AND SELECTION OF HEDGE FUNDS}

The data are obtained from Hedge Fund Research Inc., (HFR), one of the largest hedge fund databases available for academic research. We selected ten hedge fund indices for examination: four directional strategies indices, two arbitrage indices, three event-driven indices, and one fund of funds index.

\section{Market Trend (Directional/tactical) Index}

Global macro (GM) hedge funds aim to profit from changes in the global economy, as influenced by major economic trends and/or events. They use leverage and derivatives to accentuate the impact of market moves. In consequence, their expected volatilities are very high.

Emerging market (EM) hedge funds invest in equity or debt in emerging markets. There are no viable futures or other derivative products that can be used for hedging. EM hedge funds can be partially hedged via US treasury futures and currency markets but their expected volatilities are very high.

Dedicated short bias (DSB) hedge funds are specialized in the short sales of over-valued securities. Because losses on short-only positions are theoretically unlimited (since stock prices can increase indefinitely), these strategies are particularly risky.

Funds following equity hedge strategies (EH) maintain positions primarily in equity and equity derivative securities. Equity hedge managers typically maintain at least 50 percent exposure to equities, although they may in some cases be entirely invested in equities, taking both long and short positions. Managers aim to identify overvalued stocks that can be sold short.

\section{Arbitrage Index}

Equity market neutral (EMN) hedge funds aim to eliminate tend to negate the impact and risk of general market movements and their strategies can be classified into two main sub-categories: market neutral arbitrage, which attempts to hedge out most market risk by taking offsetting positions, and market neutral securities hedging, which invests equally in long and short equity portfolios, generally in the same market sectors. Due to their deep exposure to the stock market, the expected volatilities of these types of funds are generally low.

Convertible arbitrage (CA) hedge funds buy corporate convertible bonds while simultaneously short-selling the common stock of the same companies that issued the bonds. Arbitrageurs seek to take advantage of anomalies that can appear between the price of a bond that is convertible into shares and the price of these shares. The idea is to make money from the bond's yield if the bond price increases but also make money from short sales if the price of the stock decreases. Because convertible bonds and stocks can move independently from each other, this investment strategy is very risky. The expected volatility is therefore high. 


\section{Event-Driven Indices}

Event-driven (ED) hedge funds focus on price movements observed in anticipation of corporate event such as leveraged buy-outs, mergers, and hostile takeovers. The most common event-driven strategies involve distressed securities and merger arbitrage.

Merger arbitrage (MA) strategies focus primarily on opportunities in the equity and equity-related instruments of companies that are currently engaged in corporate transactions. Merger arbitrage strategies typically have over $75 \%$ of their positions in announced transactions over a given market cycle.

Multi-strategy (MS) hedge funds are typically quantitatively driven and seek to identify attractive positions that exploit spreads involving combinations of fixed income, derivatives, equities, real estate, and other instruments. Managers invest in several hedge fund strategies, promoting the diversification of risk. These strategies require more than $30 \%$ of portfolio exposure to be maintained in two or more distinct strategies.

\section{Fund of Funds Index}

Fund of Funds (FoF) hedge funds mix and match hedge funds. This blending of different strategies and asset classes aims to provide a high level of diversification and more stable long-term investment returns than any individual fund. Returns, risk, and volatility can be controlled by the mix of underlying strategies and funds.

\section{EMPIRICAL STRATEGY}

To illustrate the dynamic conditional correlation model for our purposes, let $\mathbf{x}_{t}$ be a vector containing the return, volume, and implied volatility series in the following conditional mean equation:

$\mathbf{x}_{\mathbf{t}}=\boldsymbol{\mu}_{\mathbf{t}}+\boldsymbol{\varepsilon}_{\mathbf{t}}$, where $\boldsymbol{\varepsilon}_{\mathbf{t}} \mid \boldsymbol{\Omega}_{\mathbf{t}-\mathbf{1}} \sim N\left(\mathbf{0}, \mathbf{H}_{\mathbf{t}}\right)$

(1) where $\boldsymbol{\mu}_{\mathbf{t}}=E\left[\mathbf{x}_{\mathbf{t}} \| \boldsymbol{\Omega}_{\mathbf{t}-\mathbf{1}}\right]$ is the conditional expectation of $\mathbf{x}_{\mathbf{t}}$ given the past information $\boldsymbol{\Omega}_{\mathbf{t}-\mathbf{1}}$, and $\boldsymbol{\varepsilon}_{\mathbf{t}}$ is a vector of errors in autoregression $\operatorname{AR}(1)$. Both are assumed to have conditional multivariate normal distributions with means of zero and a variance-covariance matrix $\mathbf{H}_{\mathbf{t}} \equiv\left\{h_{i j}\right\}$. Assuming that the return, volume, and implied volatility series $\mathbf{x}_{t}$ are determined by the information set available at time $\mathrm{t}-1$, the model may be estimated using maximum likelihood methods, subject to the requirement that the conditional covariance matrix, $\mathbf{H}_{\mathbf{t}}$, be positive for all values of $\boldsymbol{\varepsilon}_{\mathbf{t}}$ in the sample. We also assume that $\boldsymbol{\mu}_{\mathbf{t}}$ takes the following form:

$\mu_{i, t}=\Phi_{0}+\Phi_{1} x_{i, t-1}, \forall \mathrm{i}$

(2) where $\Phi_{1}$ measures the ARCH effect in the data series. In the traditional multivariate GARCH framework, the conditional variance-covariance matrix can be written as:

$\mathbf{H}_{\mathbf{t}}=D_{\mathbf{t}} \mathbf{R}_{\mathbf{t}} D_{\mathbf{t}}$, where $D_{\mathbf{t}}=\operatorname{diag}\left\{\sqrt{h_{i t}}\right\}$

(3) where $h_{i t}$ is the estimated conditional variance. This is calculated through the individual standard univariate $\operatorname{GARCH}(1,1)$ models as follows:

$h_{i t}=\omega_{i}+\alpha_{i} \varepsilon_{i, t-1}^{2}+\beta_{i} h_{i, t-1} \quad \forall i$

(4) where $\mathbf{R}_{\mathbf{t}}$ is the time-varying conditional correlation coefficient matrix. According to the specifications in equation (4), each market's variance is modeled as a function of the constant, the square of last period's own residuals $\varepsilon_{i, t-1}^{2}$, and the lagged conditional variance $h_{i, t-1}$. After the basic construction above, the dynamic correlation coefficient matrix of the DCC model can be further defined by: 


$$
\begin{aligned}
& R_{t}=\left[\operatorname{diag}\left(Q_{t}\right)\right]^{-\frac{1}{2}} Q_{t}\left[\operatorname{diag}\left(Q_{t}\right)\right]^{\frac{1}{2}} \\
& Q_{t}=\left(q_{i j, t}\right) \\
& {\left[\operatorname{diag}\left(Q_{t}\right)\right]^{-\frac{1}{2}}=\operatorname{diag}\left(\frac{1}{\sqrt{q_{11, t}}}, \frac{1}{\sqrt{q_{22, t}}} \cdots \frac{1}{\sqrt{q_{10,10, t}}}\right)}
\end{aligned}
$$

\section{RESULTS}

Figure 1 reports the conditional correlations between hedge fund strategies and the S\&P 500 index, as estimated by the asymmetric DCC-GARCH model. The figure shows that the dynamic conditional correlations vary over time between being positive and negative. This result is consistent with the findings of Brooks and Kat (2002), Kat and $\mathrm{Lu}$ (2002), and Liang (2004) show that correlation vary in different market conditions.

Considering periods of crisis, such as during the Asian (June 1997), internet bubble (March 2000), subprime mortgage (July 2007), and global financial crises (September 2008), figure 1 reports that most hedge fund strategies are highly correlated with the S\&P 500 stock index, with the exceptions of the DSB and GM strategies. This finding is in line with Forbes and Rigobon (2002), who show that the correlations between hedge funds and global stocks increase during crisis periods due to the corresponding increases in the volatility of global equity markets. Similarly, Abugri and Dutta (2009) find significant correlations with benchmark assets during the pre-2007 period and overwhelmingly insignificant correlations during the post-2006 period. Boyson et al. (2010) find evidence that adverse funding and liquidity shocks significantly affect hedge fund performance.

The decreased correlations of the DSB and GM strategies with the S\&P 500 index, which are explained by their negative equity market exposure, illustrate the power of the diversification employed by these strategies in allowing them to outperform markets during downturns. It is noteworthy that the correlation between the examined stock index and the majority of strategies is most significant during the 2007-2008 crisis period. This allows us to conclude that this latest crisis had a greater impact on hedge fund returns than other crises. These results confirm our previous findings.

Figure 2 summarizes the monthly stock returns and conditional variances estimated by the DCC-GARCH model. From the returns of different hedge funds strategies, the presence of clustering volatility can be recognized: large (small) changes in strategies tend to be followed by large (small) changes of the same or opposite sign. The conditional variance varies between two states: the first corresponds to recessions, characterized by high volatility and low returns, and the second corresponds to periods of expansion, characterized by low volatility and high yields.

\section{CONCLUSION}

The present study aimed to analyze the correlations between hedge funds and passive asset classes (bonds and equities) over economic cycles containing critical events for hedge funds, such as the Asian crisis in 1998, the bursting of the technology bubble in 2000, and the sub-prime mortgage crisis in 2007 . The results indicate that, in general, some hedge funds tend to outperform the examined passive benchmarks, making them seem very attractive from the point of view of investors. Institutional investors and high-net-worth individuals have put significant amounts of money into hedge funds, seeking the high returns and diversification benefits promised by hedge fund managers (see Fung et al., 2008). However, during the sub-prime mortgage crisis, the hedge fund industry was unable to generate positive returns (independent of market conditions). Hence, in contrast to other research (Fung and Hsieh, 1997; Kat and Lu, 2002), this study finds that hedge funds have greater correlations with passive asset classes than previously thought, especially during periods of recession. Although there is evidence that hedge funds are affected by financial market distress, it seems that hedge funds have been more significantly impacted by the recent financial crisis than by previous stress events. In future research, we hope to discuss potential reasons for the increased sensitivity of hedge funds to market distress, including the increasing size of the hedge fund industry, securitization, short-sale bans, and the application of forced sales. 
Figure 1. Hedge fund dynamic correlation with SP500
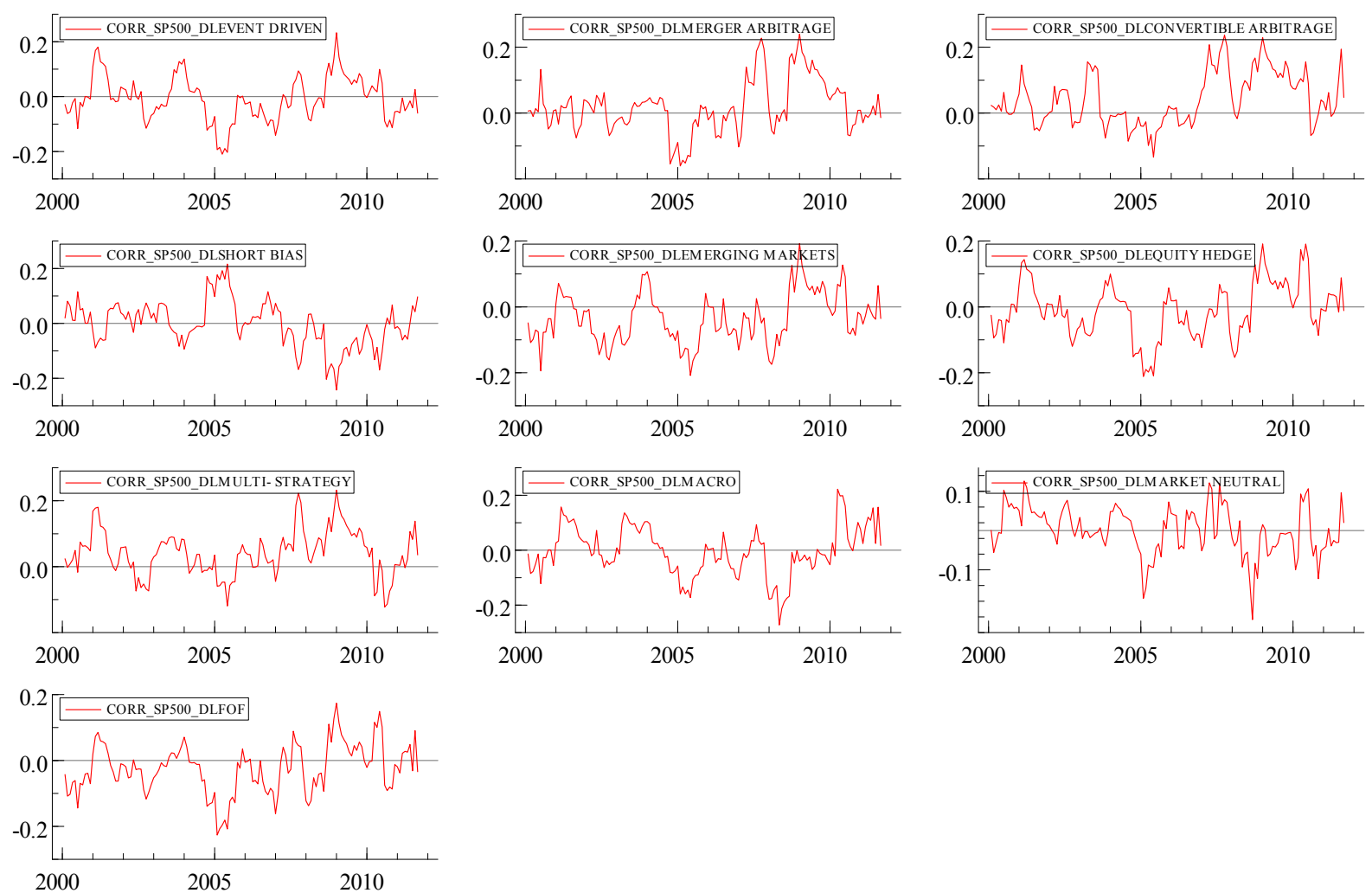

Figure 2. Hedge fund monthly returns volatility
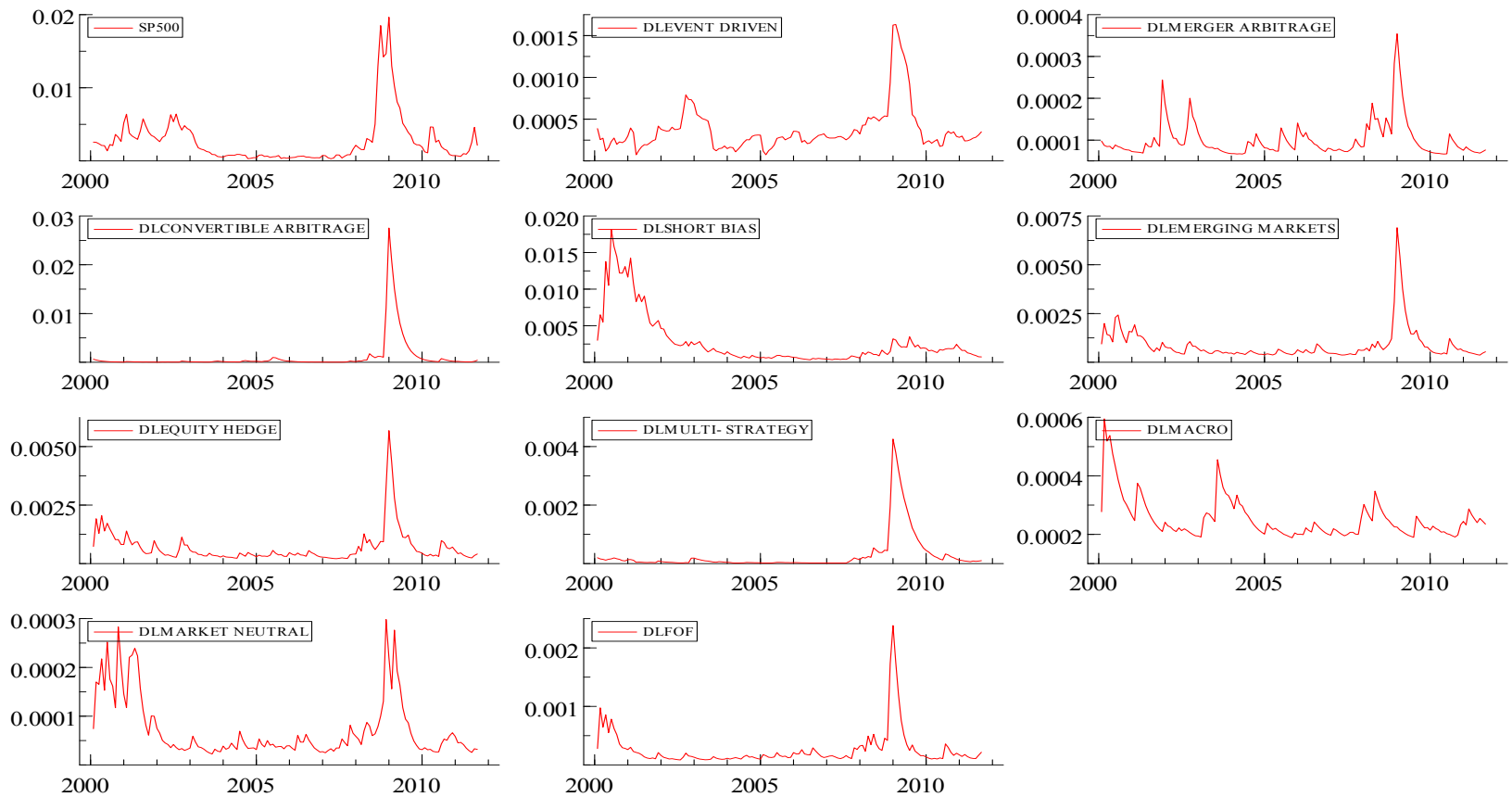


\section{AUTHOR INFORMATION}

Khaled Guesmi, Ph.D is an Associate Professor of Finance in IPAG Business School. He is also an Associate Researcher at Economix, University of Paris Ouest Nanterre la Défense. His principal research areas concern finance in emerging markets. His most recent articles are forthcoming and published in refereed journals such as Economic Modelling, Energy Economics, Economics Bulletin, Journal of Banking and Finance, Applied Economics, Journal of Applied Business Research, Energy Study Review, Journal of International Financial Markets, Institutions \& Money... E-mail: khaled.guesmi@ipag.fr (Corresponding author)

Saoussen Jebri, Ph. D, is a Business Analyst in Société Générale Group. E-mail: $\underline{\underline{s a o u s s e n ~ j e b r i @ y a h o o . f r ~}}$

Abdelkarim Jabri, Ph.D. in Economics, is professor at LERMA (ENCGO), Mohammed First University, Oujda, Morocco. His research is nonlinear Panel Focuses and Time Series Econometrics Applied to Finance, Macroeconomics, and International Trade. E-mail: jkarim7@yahoo.fr.

Frédéric Teulon, Ph. D is the head of the research center of IPAG Business School. His research focuses on macroeconomics, microeconomics, and international Finance. His most recent articles are forthcoming and published in refereed journals such as Economic Modelling, Economics Bulletin, International Economics, Applied Financial Economics, Journal of Accounting and Finance. E-mail: f.teulon@ipag.fr

\section{REFERENCES}

Abugri, B. and Dutta, S. (2009), Emerging market hedge funds: Do they perform like regular hedge funds?, Journal of International Financial Markets, Institutions \& Money, 19 (5), 834-849.

Agarwal, V. and Naik, N. (2004), Risk and portfolio decisions involving hedge funds, Review of Financial Studies, 17 (1), 63-98.

Boyson, N., Stahel, C. and Stulz, R. (2010), Hedge Fund Contagion and Liquidity Shocks, Journal of Finance, 65 (5), 1789-1816.

Brooks, C. and Kat, H. (2002), The Statistical Properties of Hedge fund Index Returns and their Implications for Investors, The Journal of Alternative Investments, 5, 26-44.

Capocci, D., Corhay, A. and Hubner, G. (2005), Hedge fund Performance and Persistence in Bull and Bear Markets, European Journal of Finance, 11 (5), 361-392.

Forbes, K. and Ribogon, R. (2002), No Contagion, Only Interpendence: Measuring Stock Market Co-Movements, The Journal of Finance, 57 (5), 2223-2261.

Fung, W. and Hsieh, D. (1997), Empirical Characteristics of Dynamic Trading Strategies: The Case of hedge funds, Review of Financial Studies, 10, 275-302.

Fung, W., Hsieh, D., Naik, N. and Ramadorai, T. (2008), Hedge funds: Performance, risk, and capital formation, Journal of Finance, 63 (4), 1777-1803.

Kat, H. and Lu, S. (2002), An Excursion into the Statistical Properties of Hedge Fund Returns, Working paper.

Liang B. (2004), On the Performance of Alternative Investments: CTAs, Hedge funds and FoF, Journal of Investment Management, 2, 76-93.

Mitchell, M. and Pulvino, T. (2001), Characteristics of Risk and Return in Risk Arbitrage, Journal of Finance, 56 (6), 2135-2175. 